\title{
Body growth, mitochondrial enzymatic capacities and aspects of the antioxidant system and redox balance under calorie restriction in young turbot (Scophthalmus maximus, L.)
}

\author{
Doris Abele, Daniel Roecken, Martin Graeve \& Bela H Buck \\ Alfred Wegener Institute for Polar and Marine Research, Bremerhaven, Germany \\ Correspondence: D Abele, Alfred Wegener Institute for Polar and Marine Research, Marine Ecophysiology, Am Handelshafen 12, 27570 \\ Bremerhaven, Germany. E-mail: Doris.Abele@awi.de
}

\begin{abstract}
Calorie restriction (CR) without undernutrition has been found to enhance stress resistance and life span in endotherms and ectotherms. We investigated the effect of $30 \%$ reduction in food offering on growth, aerobic capacities and oxidative stress parameters in young turbot (Scophthalmus maximus, L.).

No differences in body weight, length and hepatosomatic index between the ad libitum (AL)-fed and the CR group occurred after 55 days of diet application. Of the mitochondrial marker enzymes, only citrate synthase (CS) activity in the liver was reduced under $\mathrm{CR}$, whereas muscle CS activity and cytochrome oxidase (CCO) activity in both tissues remained the same in both feeding groups. The concentration of reduced glutathione increased significantly during feeding in muscle of CR fish, resulting in a more reduced glutathione redox ratio (GSH/GSSG) compared with AL fish muscle. Thiobarbituric acidreactive lipid hydroperoxides (lipid peroxidation) but not protein carbonyl content (protein oxidation) was significantly reduced in CR fish muscle. Liver oxidative stress parameters did not vary significantly between experimental feeding groups.

We conclude that $30 \%$ CR over 8 weeks has no adverse effect on young turbot. On the contrary, CR supports a reduced tissue oxidation state and reduces accumulation of lipid peroxidation products in muscle at sustained muscular aerobic capacity.
\end{abstract}

Keywords: turbot, calorie restriction, mitochondria, glutathione, oxidative stress

\section{Introduction}

Growth performance in response to diet of commercially cultured fish species, such as turbot (Scophthalmus maximus, L.), is of great concern to understand the production cycle, to ease management, and to calculate costs in aquaculture. Fish feeds are usually the largest variable cost item in an intensive culture system (Shepherd \& Bromage 1988). Intensively farmed fish require high-protein feeds (Randall, Bolis \& Agradi 1990), which originate mainly from fishmeal (Mock, White \& Wagener 2001). Owing to the global use of fishmeal and the increasing demand from aquaculturists, the prices of fishmeal are increasing. In this context, it could become important to improve feeding and stocking management.

Because of the high variation in food availability in natural aquatic systems, fish are adapted to survive extended periods of starvation. Variable degrees of starvation during ontogeny lead to variable growth rates (Morales, Perez-Jimenez, Hidalgo, Abellán \& Cardenete 2004). In several cold and warm water fish species, phases of rapid growth follow slow growth during food restriction, a so-called compensatory growth phase (Zhu, Cui, Ali \& Wootton 2001; Skalski, Picha, Gilliam \& Borski 2005). Moreover, it is debated whether ad libitum (AL) feeding, as it is practiced in aquaculture to ensure high production output, is healthy for the cultured organisms. Studies with AL-fed primates suggest that this is not the case (Bodkin, Alexander, Ortmeyer, Johnson \& Hansen 2002; Lamming, Wood \& Sinclair 2004). Gamperl and Farrell (2004) report fish to be frequently overfed 
under aquaculture conditions with ensuing fat depositions around the heart, cardiac deformities and arteriosclerosis. It can be inferred that these fish, if kept alive to await natural death, would have a shorter life expectancy than wild fish in the absence of predators.

Calorie restriction (CR) is defined as a dietary regime low in calories without undernutrition (Koubova \& Guarente 2003). Calorie restriction is the only scientifically established means by which a substantial extension of maximum life span can be achieved in most, if not all, heterotrophic organisms tested (Sohal \& Weindruch 1996, also reviewed in Warner \& Starke-Reed 1997). This is partly explained by a reduction in the ad-hoc production of reactive oxygen species (ROS) by (isolated) mitochondria in CR animals, which can decline to less than half that of non-CR animals (Warner \& Starke-Reed 1997; Weindruch, Keenan, Carney, Fernandez, Feuers, Floyd, Halter, Ramsey, Richardson, Roth \& Spindler 2001). The reduction in ROS formation is not simply a consequence of lower respiration rates, as CR, after an initial adaptive phase, does not reduce steadystate metabolic rates (Koubova \& Guarente 2003). Instead, either less ROS are formed by mitochondria during CR, or higher antioxidant protection, including the tissue redox buffer glutathione, is achieved under limited calorie intake. In rodents, CR causes a reduction in the average daily body temperature (Duffy, Feuers, Leakey, Nakamura, Turturro \& Hart 1989), which may accentuate the diet-induced slow-down of mitochondrial ROS production.

Cellular production of ROS is inversely correlated with maximum life span at the intra-specific level, and even in inter-specific comparisons $(\mathrm{Ku}$, Brunk \& Sohal 1993). However, the control of mass-specific ROS formation is only one facet of the life-prolonging effect of CR. Characteristic changes during steadystate CR are neuroendocrine changes of the insulin/ IGF-1 signalling pathway, a more intensive turnover of body protein after depletion of glycogen reserves and changes in gene expression (for a review, see Weindruch et al. 2001; Koubova \& Guarente 2003; Stuart \& Brown 2006). The overall strategy during CR seems to be divergence of energy allocation from fecundity to body maintenance and stress resistance. Many invertebrates, invertebrate larvae and laboratory rodents show enhanced resistance to a range of stresses and prolonged life expectancy under CR (Kirkwood \& Austad 2000; Weindruch et al. 2001; Stuart \& Brown 2006).
Several studies investigated the effect of calorie restriction and starvation on the metabolic shift from lipogenesis to $\beta$-oxidation of fatty acids in cold water fish (Guderley, Lapointe, Bédard \& Dutil 2003; Martínez, Guderley, Dutil, Winger, He \& Walsh 2003). Few papers, so far, have included oxidative stress parameters (Guderley et al. 2003; Pascual, Pedrajas, Toribio, Lopez-Barea \& Peinado 2003; Morales et al. 2004). Moreover, the reports are difficult to compare because different parameters were analysed and food limitation was applied in different ways in the different papers.

In the present study, we exposed young turbot to a calorie-restricted diet ( $30 \%$ less than $\mathrm{AL}$ ) to examine how young, rapidly growing stages respond to CR.We investigated the effects on white muscle, which represents a major proportion of body mass, and is functionally important for sustained swimming activity, and, in the liver, the metabolically most active and storage tissue. Specifically, we were interested in observing whether body growth was retarded in the short term and whether or not mitochondrial enzymatic capacities [cytochrome c oxidase (CCO) and citrate synthase (CS)] were retained in CR turbot. We examined the changes in fatty acid composition in the liver to observe whether lipid stores were stocked with dietary lipids during CR feeding. Additionally, two oxidative stress parameters, protein carbonylation and formation of thiobarbituric acid-reactive lipid hydroperoxides (TBARS), were quantified in CR and AL fish as markers for oxidative damage of proteins and lipids. The glutathione status (reduced GSH: oxidized GSSG) was measured to examine whether CR fish were able to stabilize the cellular redox environment, and whether or not reduced glutathione also plays a role as an antioxidant.

Scrutinizing the approach of calorie restriction for young turbot, the results from this study may provide valuable information for future management concepts in aquaculture. If the approach of AL feeding leads to surfeit turbot with high-calorie food, this may eventually impinge on the profitability of fish farming.

\section{Materials and methods}

\section{Origin of experimental animals and holding unit}

In this experiment, juvenile turbot $(n=170$, length: $11 \mathrm{~cm} \pm 0.66$ ), reared at Venø fish farm, Struer, at the Limfjord in Denmark, were shipped to the Alfred 
Wegener Institute on 24 May 2004. The fish were maintained at $15^{\circ} \mathrm{C}( \pm 0.7)$ water temperature in a common recirculation system. The process water was treated by a typical cleaning unit containing a hydrocyclone for particle clearance, a biofilter to oxidize ammonium $\left(\mathrm{NH}_{4}^{+}\right)$and an ozone-driven protein skimmer. As no de-nitrification of the water was performed, parts of the process water (about $20 \%$ of the total volume) needed to be exchanged at regular intervals. Light was provided using a $36 \mathrm{~W}$ fluorescent daylight tube at a 12:12 light/dark cycle. Water in the holding tanks $(87.5 \times 78 \mathrm{~cm}, 150 \mathrm{~L})$ was kept aerated ( $>80 \%$ saturation), and the salinity was adjusted with artificial salt (Tropic Marin ${ }^{B}$, Dr Biener GmbH) to $25.3 \%$ o ( \pm 0.5 ). Twice a day, fish were fed with dry pellets of about $4 \mathrm{~mm}$ diameter (DAN-EX 1562, BioMar, Brande, Denmark; $58 \%$ protein, $15 \%$ fat and $10.5 \%$ carbohydrate). The remaining food pellets and fish faeces were removed from the tanks when fish stopped eating.

\section{Experimental set up for the feeding experiment}

Untagged fish $(n=170)$ were evenly distributed into two separate tanks and were maintained without feeding for 2 weeks until the start of the experiment. Inorganic nutrient levels $\left(\mathrm{NH}_{4}^{+}, \mathrm{NO}_{2}^{-}, \mathrm{NO}_{3}^{-}\right)$were recorded daily using photometric test systems (HachLange, Düsseldorf, Germany) and water was exchanged when limit values were reached $\left(\mathrm{NH}_{4}\right.$ : $0.5 \mathrm{mg} \mathrm{L}^{-1}, \mathrm{NO}_{2}: 0.5 \mathrm{mg} \mathrm{L}^{-1}$ and $\mathrm{NO}_{3}: 100 \mathrm{mg} \mathrm{L}^{-1}$ ). At no time did $\mathrm{NH}_{4}^{+}$and $\mathrm{NO}_{2}^{-}$levels exceed the limit values; however, frequent water exchanges were necessary to maintain a low $\mathrm{NO}_{3}^{-}$concentration. $\mathrm{pH}$ was controlled daily and adjusted to between 7.5 and 8.2 using calcium hydroxide.

At the beginning of the experiment, fish were fed $2 \%$ of the overall biomass twice a day at 10:00 and 15:00 hours. On 8 July 2004, the mean weight of experimental fish amounted to $23.06 \pm 0.66 \mathrm{~g}$ and the mean length to $11.46 \pm 4.77 \mathrm{~cm}(n=36$ subsample). Starting on 8 July 2004, one group of fish $(n=85)$ was fed AL group twice per day. Net consumption of pellets in the AL group was calculated as offered pellet amount minus the amount rejected by the fish. The remaining fish $(n=85)$ represent the CR group because they received $30 \%$ less pellet weight than the AL group, on each day. This feeding experiment lasted 2 months. The weight and length of 10 randomly collected individuals from each group were measured every 2 weeks. The weight and length recordings of 36 randomly picked individuals from both feeding groups were carried out on 13 September 2004 at the end of the experiment.

Animals for biochemical analyses were killed by a cut through the spine and immediately dissected. The liver and a piece of white muscle were freeze-clamped in liquid nitrogen and kept at $-80^{\circ} \mathrm{C}$ until analysis. Before freezing, liver weight was recorded. To do so, the liver was transiently stored on ice. The time between sampling and freezing was $<1 \mathrm{~min}$.

\section{Mitochondrial enzymes}

For measurements of mitochondrial enzymes cytochrome-c oxidase (CCO: E.C. 1.9.3.1, end oxidase of respiratory chain) and citrate synthase (CS: E.C. 4.1.3.7, enzyme of the citric acid cycle), frozen samples of liver and muscle were ground in liquid nitrogen and homogenized with a glass homogenizer (Nalgene, Fisher Scientific, Pittsburgh, PA, USA) in Tris-HCl buffer [20 mM Tris-HCL, $1 \mathrm{mM}$ EDTA, 0.1\% (v/v) Tween ${ }^{\mathbb{B}}$ 20, pH 7.4] 1:8 (w/v). For CCO measurements, homogenates were centrifuged for $10 \mathrm{~min}$ at $1000 \mathrm{~g}$ and $0{ }^{\circ} \mathrm{C}$. The $\mathrm{CCO}$ activity was determined according to Moyes, Mathieu-Costello, Tsuchiya, Filburn and Hansford (1997) by measuring the oxidation of reduced cytochrome $\mathrm{c}$ at $550 \mathrm{~nm}$ in $20 \mathrm{mM}$ Tris-HCL buffer with $0.5 \%$ Tween 20, pH 8.0. Fully reduced cytochrome $\mathrm{c}$ was prepared by reducing a $1 \mathrm{mM}$ stock solution with sodium di-thionide in phosphate buffer (10 mM KPi, pH 7.0 with $1 \mathrm{mM}$ EDTA). The buffer was previously purged with $\mathrm{N}_{2}$. Dithionide was removed using a Sephadex G-25 absorber column over which the cytochrome $\mathrm{c}$ solution was filtered through centrifugation at $2000 \mathrm{~g}$ for $2 \mathrm{~min}$ at $0{ }^{\circ} \mathrm{C}$. Reduced cytochrome $\mathrm{c}$ was collected into brown flasks and could be stored frozen for at least 4 weeks. Activity was calculated using the millimolar extinction coefficient $\varepsilon_{550} \mathrm{mM} 19.1 \mathrm{mM}^{-1} \mathrm{~cm}^{-1}$.

Homogenates for CS activity were sonicated for 15 min in a Branson Sonifier 450 (Branson, Danburg, CT, USA) at output control 8, Duty cycle $50 \%$ cooled to $0{ }^{\circ} \mathrm{C}$ and centrifuged at $7400 \mathrm{~g}$ for $5 \mathrm{~min}$ at $0{ }^{\circ} \mathrm{C}$. The CS activity was measured according to the method of Sidell, Driedzic, Stowe and Johnston (1987) recording the absorbance increase of $5 \mathrm{mM}$ DTNB [5,5'dithiobis(2-nitrobenzoic acid)] in $100 \mathrm{mM}$ Tris-HCL (pH 8.0), $20 \mathrm{mM}$ Acetyl-CoA and $20 \mathrm{mM} \mathrm{Ox-}$ aloacetat at $412 \mathrm{~nm}$. Activity was calculated using the millimolar extinction coefficient $\varepsilon_{412}$ of $13.61 \mathrm{mM}^{-1} \mathrm{~cm}^{-1}$. 


\section{Oxidative stress parameters}

For protein carbonylation (after Levine, Garland, Oliver, Amici, Climent, Lenz, Ahn, Shaltiel \& Stadtman 1990), tissue samples were homogenized in $50 \mathrm{mM}$ HEPES buffer, pH 7.4, containing $125 \mathrm{mM} \mathrm{KCl}$, $1.25 \mathrm{mM}$ EDTA, $0.6 \mathrm{mM} \mathrm{MgSO}_{4}$ and protease inhibitors $\left(0.5 \mu \mathrm{g} \mathrm{mL}^{-1}\right.$ leupeptine, $0.7 \mu \mathrm{g} \mathrm{mL}^{-1}$ pepstatine, $40 \mu \mathrm{g} \mathrm{mL}^{-1} \quad$ phenylmethylsulphonyl fluoride, $0.5 \mu \mathrm{g} \mathrm{mL}^{-1}$ aprotinin) and centrifuged at $100000 \mathrm{~g}$ for $15 \mathrm{~min}$ at $4{ }^{\circ} \mathrm{C}$. Supernatants were incubated at room temperature for $1 \mathrm{~h}$ with $10 \mathrm{mM}$ 2,4-dinitrophenylhydrazine (DNTP) dissolved in $2 \mathrm{M} \mathrm{HCl}$ to allow DNTP to bind to the carbonyl groups. Blanks were run with $\mathrm{HCl}$ only. Afterwards, proteins were precipitated with $0.2 \mathrm{~mL} \mathrm{100 \%} \mathrm{trichloroacetic} \mathrm{acid} \mathrm{(TCA)}$ and centrifuged for $10 \mathrm{~min}$ at $11000 \mathrm{~g}$. The protein pellet was washed three times with ethanol:ethylacetate (1:1), resuspended in guanidine hydrochloride (6 $\mathrm{M}$ in $20 \mathrm{mM}$ potassium phosphate, $\mathrm{pH}=2.5$ ) and incubated at $37^{\circ} \mathrm{C}$ until complete resuspension. The carbonyl content was measured spectrophotometrically in the resulting suspension at $360 \mathrm{~nm}$ (molar extinction coefficient $\varepsilon=22000 \mathrm{M}^{-1} \mathrm{~cm}^{-1}$ ). To relate carbonyl content to the amount of extracted proteins in each sample, the protein content was subsequently measured with the method of Bradford (1976).

The TBARS concentrations were determined according to the method of Uchiyama and Mihara (1978). Deep-frozen tissues were ground and homogenized in 1:10 (w/v) $0.2 \% \mathrm{H}_{3} \mathrm{PO}_{4} .0 .4 \mathrm{~mL}$ of homogenate was mixed with $0.4 \mathrm{~mL}$ of $1 \%$ thiobarbituric acid (TBA). Individual blanks were prepared by replacing the TBA solution with $3 \mathrm{mM} \mathrm{HCl}$. The $\mathrm{pH}$ was adjusted to 1.6. The samples were heated to $100{ }^{\circ} \mathrm{C}$ for $1 \mathrm{~h}$. After cooling to room temperature, $2 \mathrm{~mL}$ butanol was added to the samples and blanks. After mixing for $40 \mathrm{~s}$, the butanol phase was separated by centrifugation for $5 \mathrm{~min}$ at $14000 \mathrm{~g}$ and the concentration of the lipidhydroperoxide-TBA acid complex in solution was measured as the difference in absorbance between 532 and $600 \mathrm{~nm}$. The concentration was quantified from a previously obtained calibration curve.

\section{Determination of reduced (GSH) and oxidized (GSSG) glutathione by high-performance liquid chromatography (HPLC)}

The content of GSH and GSSG was determined according to the method of Fariss and Reed (1987). Fro- zen tissue of muscle and liver was ground in liquid nitrogen and the resulting powder was homogenized in 1:10 (w:v) pre-cooled PCA (10\% containing $2 \mathrm{mM}$ bathophenanthroline-disulphonic acid). After centrifugation at $15000 \mathrm{~g}$ for $5 \mathrm{~min}$ at $4{ }^{\circ} \mathrm{C}, 500 \mu \mathrm{L}$ of the supernatant was mixed with $10 \mu \mathrm{L} \mathrm{pH}$ indicator [1 mM m-cresol purple sodium salt containing $0.5 \mathrm{M}$ iodoacetic acid (IAA)]. Fifty microlitres $1 \mathrm{mM} \gamma$-glutamyl-glutamate (in $0.3 \%$ PCA) was added as an internal standard. The $\mathrm{pH}$ was adjusted to 8.5 with $5 \mathrm{M}$ $\mathrm{KOH}$ (containing $0.3 \mathrm{M} \mathrm{N}$-morpholine-propanesulphonic acid). The mixture was incubated at room temperature for $45 \mathrm{~min}$, to allow IAA to bind GSH. Subsequently, samples were centrifuged for $5 \mathrm{~min}$ at $15000 \mathrm{~g}$ and $4{ }^{\circ} \mathrm{C}$. Three hundred microlitres of the supernatant was added to double the amount of $1 \%$ 1-fluor-2,4-dinitrobenzene (diluted in 100\% ethanol, HPLC grade) and derivatized in dark vials at room temperature over $24 \mathrm{~h}$. After centrifugation at $7500 \mathrm{~g}$ for $1 \mathrm{~min}$ at $4{ }^{\circ} \mathrm{C}$ and filtration through $0.2 \mu \mathrm{m}$ nylon membrane filters, samples were stored in dark HPLC vials at $-20{ }^{\circ} \mathrm{C}$.

The HPLC determination was carried out on a Beckmann Coulter HPLC System using a $\mathrm{NH}_{2}-$ spherisorp column, $5 \mu \mathrm{m} 240 \times 4 \mathrm{~mm}$ (Waters, Germany). Solvent A: $80 \%$ methanol and solvent B: sodium acetate stock in 80\% methanol (20:80). Sodium acetate stock was prepared by dissolving $500 \mathrm{~g}$ Na-acetate in $224 \mathrm{~mL}$ Milli-Q water and $695 \mathrm{~mL}$ of concentrated HPLC-grade acetic acid. The gradient programme consisted of a 10-min hold at $90 \% \mathrm{~A}$, followed by a $25-\mathrm{min}$ linear gradient to $25 \%$ $\mathrm{A}$ at a flow rate of $1 \mathrm{~mL} \mathrm{~min}^{-1}$ and $2.3-2.8 \mathrm{kpsi}$ backpressure. Peaks were recorded with a photodiode array detector at $365 \mathrm{~nm}$.

\section{Lipid analyses}

Liver sample dry mass was determined after lyophilization for $48 \mathrm{~h}$ and then total lipids were extracted according to the method of Folch, Lees and Sloane Stanley (1957). The lipid content was determined gravimetrically and expressed as total lipid mass $(\mathrm{mg})$ and in per cent of dry mass (\% DM). The fatty acid composition of total lipids was determined by gas chromatography (GC), without differentiation of individual lipid classes (Kattner \& Fricke 1986). Briefly, an aliquot of the total lipid extract was hydrolysed in methanol containing 3\% concentrated sulphuric acid, and fatty acids were converted to methyl esters (FAME) by transesterification at $80{ }^{\circ} \mathrm{C}$ 
for $4 \mathrm{~h}$. After extraction with hexane, FAME were analysed with a gas liquid chromatograph (Agilent 6890 ) on a $30 \mathrm{~m} \times 0.25 \mathrm{~mm}$ i.d. wall-coated open tubular column (film thickness: $0.25 \mu \mathrm{m}$, liquid phase: DB-FFAP) using temperature programming (Kattner \& Fricke 1986; Graeve, Albers \& Kattner 2005). The fatty acids were identified using standard mixtures and, if necessary, additional confirmation was performed by GC-MS. Fatty acids were grouped according to their presumed origin: the 16:0, 20:5(n3), 22:6(n-3) fatty acids are membrane-bound fatty acids (MbFA), 16:1(n-7), 16:X polyunsaturated fatty acids (PUFA), 18:1(n-7) and 18:X PUFA are of dietary origin (DietFA) $(X=2-4$ double bonds), long-chain monounsaturated fatty acids, especially 20:1 and 22:1 fatty acids (both isomers) (MUFA) and saturated fatty acids (SAFA).

\section{Statistical analyses}

All data were tested for variance inhomogeneity (Levene test, $P<0.05)$ using statistica 6.1. (Stat. Soft.). Significant differences between group means were analysed using the T-test $(P<0.05)$. Datasets involving repeated sampling during the experiment (weight and length) that showed variance inhomogeneity were log-transformed before testing by multiple regression analysis for significant differences between feeding groups.

Prognostic growth models of weight and length gain in both feeding groups were calculated from log-transformed weight and length data for AL and CR groups separately by omitting the start value. The unified growth model included start and end values. The models were tested for variance of inhomogeneity and through regression analysis. Significant differences between separate and unified model were determined using the $F$-test $(P<0.05)$.

\section{Results}

\section{Fish growth and response of biochemical parameters to $C R$ and $A L$ feeding}

Neither final animal length nor weight differed between AL-fed and CR groups after 8 weeks (55 days) of differential feeding (Table 1). The final liver weight was significantly higher in the AL-fed than in CR fish. The hepatosomatic index (HIS: per cent liver of overall body weight) was three times higher in AL and CR fish compared with the starting value, but without
Table 1 Growth and condition factors in start and feeding groups of young turbot

\begin{tabular}{lcrc}
\hline & Start & Ad libitum fed & Calorie restriction \\
\hline Body length & $11.46 \pm 0.66$ & $17.76 \pm 1.15^{*}$ & $17.40 \pm 1.17^{*}$ \\
Body weight & $23.06 \pm 4.77$ & $113.33 \pm 26.12$ & $101.61 \pm 24.84$ \\
Liver weight & $0.146 \pm 0.05$ & $2.195 \pm 0.68^{*}$ & $1.73 \pm 0.77 * \dagger$ \\
HSI (\%) & $0.63 \pm 0.07$ & $1.94 \pm 0.12^{*}$ & $1.70 \pm 0.27^{*}$ \\
Lipid content & $17.7 \pm 6.2$ & $21.6 \pm 2.8$ & $22.0 \pm 3.6$ \\
$(\%)$ & & & \\
\hline
\end{tabular}

Data are means \pm SEM.

*Significant difference between ST and feeding groups.

$\dagger$ Between both feeding groups, $n=36$, with the exception of lipid content where $n=8$; significance level: $P<0.05$.

Table 2 Activities of mitochondrial enzymes citrate synthase (CS) and cytochrome-c oxidase (CCO) in liver and muscle of ad libitum and calorie-restricted turbot

\begin{tabular}{llcl}
\hline & Start & Ad libitum fed & $\begin{array}{l}\text { Calorie } \\
\text { restriction }\end{array}$ \\
\hline Liver & & & \\
$\mathrm{CS}\left(\mathrm{Ug}^{-1} \mathrm{fwt}\right)$ & $1.91 \pm 0.71$ & $1.6 \pm 0.22$ & $1.29 \pm 0.16 \dagger$ \\
$\mathrm{CCO}\left(\mathrm{Ug} \mathrm{g}^{-1} \mathrm{fwt}\right)$ & $5.14 \pm 1.38$ & $2.09 \pm 0.60^{*}$ & $2.60 \pm 0.77^{*}$ \\
$\mathrm{CCO}: \mathrm{CS}$ & $2.93 \pm 1.13$ & $1.33 \pm 0.44^{*}$ & $2,06 \pm 0.7 \dagger$ \\
Muscle & & & \\
$\mathrm{CS}\left(\mathrm{Ug} \mathrm{g}^{-1} \mathrm{fwt}\right)$ & $0.50 \pm 0.14$ & $0.88 \pm 0.03^{*}$ & $0.72 \pm 0.19 * \dagger$ \\
$\mathrm{CCO}\left(\mathrm{Ug} \mathrm{g}^{-1} \mathrm{fwt}\right)$ & $0.74 \pm 0.11$ & $1.05 \pm 0.19^{*}$ & $0.96 \pm 0.16^{*}$ \\
$\mathrm{CCO}: \mathrm{CS}$ & $1.38 \pm 0.35$ & $1.19 \pm 0.23$ & $1.20 \pm 0.34$ \\
\hline
\end{tabular}

Enzyme activities are given as $\mathrm{Umg}^{-1}$ wet weight.

Data are means \pm SEM, $n=8$.

*Significant difference between ST and feeding groups.

$\dagger$ Between feeding groups; significance level: $P<0.05$.

$\mathrm{CCO}$, cytochrome c oxidase, CS, citrate synthase.

significance between feeding groups, and the liver lipid content (\%) remained constant between the start and end of the feeding experiment in both groups (Table 1).

The activities of mitochondrial marker enzymes in young turbot (Table 2) were in the range reported for juvenile cod in white muscle and liver tissue by Couture, Dutij and Guderley (1998), and also comparable to data from adult marine fish (e.g. Yang \& Somero 1993). During the feeding experiment, liver CS activity decreased, whereas muscle CS activity increased in both diet groups. Only in liver tissue was CS activity significantly lower in CR than in AL individuals, whereas the activities in muscle did not differ between groups. At the end of the feeding experiment, liver $\mathrm{CCO}$ activity per wet weight was significantly lower $(P<0.05)$ than the starting value. In contrast, muscle CCO activity was higher in both feeding 
Table 3 Concentrations of reduced (GSH) and oxidized glutathione (GSSG) and glutathione redox ratio (GSH/ GSSG) in muscle and liver of ad libitum and calorierestricted turbot

\begin{tabular}{lccl}
\hline & Start & Ad libitum fed & Calorie restriction \\
\hline (a) Liver & & & \\
GSH $_{\text {total }}$ & $1281 \pm 264$ & $1633 \pm 278^{*}$ & $1480 \pm 173$ \\
GSH & $1112 \pm 249$ & $1504 \pm 252^{*}$ & $1352 \pm 157^{*}$ \\
GSSG & $84.8 \pm 13.6$ & $64.5 \pm 17.9^{*}$ & $63.8 \pm 13.9^{*}$ \\
GSH/GSSG & $13.2 \pm 2.7$ & $24.2 \pm 3.8^{*}$ & $21.9 \pm 4.7^{*}$ \\
(b) Muscle & & & \\
GSH & $463 \pm 72$ & $525 \pm 124$ & $532 \pm 27^{*}$ \\
GSH & $394 \pm 61$ & $395 \pm 66$ & $460 \pm 24 * \dagger$ \\
GSSG & $34.3 \pm 9.5$ & $51.6 \pm 26.7$ & $36.5 \pm 6.7$ \\
GSH/GSSG & $12.1 \pm 2.8$ & $8.4 \pm 4.5$ & $13.0 \pm 2.7 * \dagger$ \\
\hline
\end{tabular}

Glutathione concentration in $\mathrm{nmolg}^{-1}$ fwt as means \pm SEM with $n=8$; ratios are $\pm \mathrm{SD}$.

*Significant difference between ST and feeding groups.

†Between feeding groups; significance level: $P<0.05$.

groups compared with the starting value. At the end of the feeding experiment, CCO activity did not differ between AL-fed and CR fish. The $\mathrm{CCO} / \mathrm{CS}$ ratios given in Table 2 indicate that the CR fish maintained a similar (muscle) or higher (liver) respiratory capacity per unit of mitochondrial volume as the AL-fed individuals.

The overall content of reduced and oxidized glutathione per milligram tissue weight $\left(\mathrm{GSH}_{\text {total }}\right.$ Table 3) was about threefold higher in the liver compared with muscle tissue. During the feeding experiment, $\mathrm{GSH}_{\text {total }}$ as well as the content of reduced GSH increased significantly in AL group liver, whereas in the $\mathrm{CR}$ fish liver the increment of $\mathrm{GSH}_{\text {total }}$ did not reach significance. Liver GSSG content decreased significantly, and to a similar extent, in both feeding groups so that in both diet groups the liver redox ratio became significantly reduced compared with the ST group without a statistical difference between the CR and AL groups (GSH/GSSG in Table 3a). A minor increase in $\mathrm{GSH}_{\text {total }}$ was observed in white muscle of both AL and CR group, but reached significance only in the CR group. The concentration of reduced glutathione $(\mathrm{GSH})$ increased in the $\mathrm{CR}$ group $(P<0.05)$, whereas the concentration of GSSG in muscle remained unchanged between ST and CR group muscle. The GSSG values in muscle of AL fish were not statistically different because of the high SEM value. However, on calculating the redox ratio for every individual fish muscle, we found AL muscle to be significantly more oxidized than CR fish muscle at the end of the feeding experiment (GSH/GSSG in Table $3 b$ ).
Table 4 Oxidative stress indicators in ad libitum and calorie-restricted turbot. Concentration of protein carbonyls and thiobarbituric acid reactive lipid-hydroperoxides (TBARS) in liver and muscle tissue

\begin{tabular}{|c|c|c|c|}
\hline & Start & Ad libitum fed & $\begin{array}{l}\text { Calorie } \\
\text { restriction }\end{array}$ \\
\hline \multicolumn{4}{|l|}{ Liver } \\
\hline $\begin{array}{l}\text { Protein } \\
\text { carbonyls }\end{array}$ & $1.675 \pm 0.802$ & $2.664 \pm 0.734^{*}$ & $3.042 \pm 1.691$ \\
\hline $\begin{array}{l}\text { TBARS } \\
\text { Muscle }\end{array}$ & $1.518 \pm 1.025$ & $1.176 \pm 0.469$ & $1.322 \pm 0.296$ \\
\hline $\begin{array}{l}\text { Protein } \\
\text { carbonyls }\end{array}$ & $6.288 \pm 2.637$ & $3.268 \pm 1.335^{*}$ & $3.995 \pm 0.907^{*}$ \\
\hline TBARS & $0.149 \pm 0.105$ & $0.387 \pm 0.153^{*}$ & $0.210 \pm 0.079 \dagger$ \\
\hline
\end{tabular}

The concentrations of protein carbonyls in nmol $\mathrm{CO} \mathrm{mg}^{-1}$ protein and for TBARS in $\mu \mathrm{molg}^{-1}$ fwt. Data are means \pm SEM, $n=8$.

*Significant difference between ST and feeding groups.

$\dagger$ Between feeding groups; significance level: $P<0.05$.

TBARS, thiobarbituric acid reactive lipid hydroperoxides.

Protein oxidation markers (nmol CO $\mathrm{mg}^{-1}$ protein) were threefold higher in muscle than liver tissue, whereas liver TBARS ( $\mu$ molTBARS $g^{-1}$ fwt) were 10fold higher than muscle values in the turbot STgroup (Table 4). In the liver, protein carbonylation increased in both the AL group and CR group, but the increase was significant only in the AL group. The TBARS content was slightly diminished in the AL and CR feeding groups relative to the ST values. In muscle tissue of animals from both feeding groups, the protein carbonyl content was significantly reduced to about half the starting value. By contrast, lipid peroxidation in muscle tissue was significantly higher in AL fish than in the ST and in the CR group (Table 4).

\section{Lipid content and fatty acid analysis}

Whereas the overall liver lipid content remained constant between start value and both feeding groups (Table 1), differences in fatty acid composition were significant $(P<0.05)$. The typical membrane fatty acids (MbFA) (16:0, 20:5(n-3) and 22:6(n-3)) were more abundant in the ST group liver $(55 \%)$ as compared with the AL group (45\%) and CR group (47\%) (Fig. 1). The fatty acids of dietary origin (DietFA) [16:1 $(n-7), 16: X$ polyunsaturated fatty acids (PUFA), 18:1 $(n-7)$ and 18:X PUFA (X $=2-4$ Double bonds)] and long-chain monounsaturated fatty acids, especially 20:1 and 22:1 fatty acids (both isomers) (MUFA), had relatively high proportions in the AL group and 


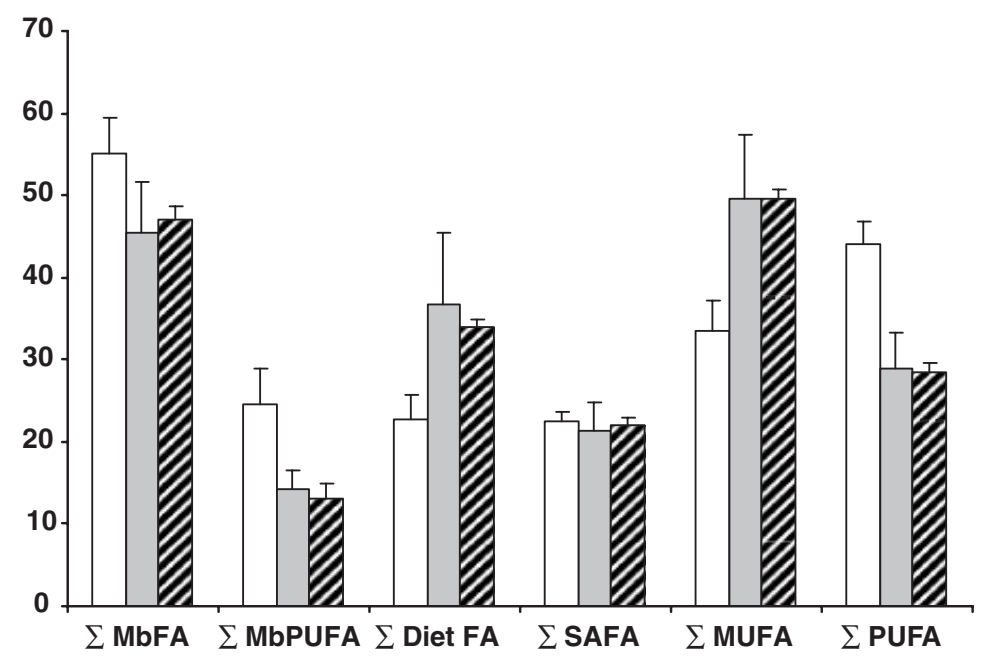

Figure 1 Fatty acid composition (mass \%) of liver tissue at the start (ST, white bar, day 36) and after 55 days of ad libitum feeding (AL, grey bar) and of 30\% calorie-restricted feeding (CR, hatched bar). Sum of membrane fatty acids (MbFA), and polyunsaturated fatty acids of membranes (MbPUFA), dietary fatty acids (Diet FA), saturated fatty acids (SAFA), monounsaturated fatty acids, polyunsaturated fatty acids. (For definition, see also materials and methods part).

CR group with $35 \%$ and $49 \%$ respectively. Saturated fatty acids (SAFA) appeared in all three groups at almost similar proportions around $22.0 \%$. The proportion of short-chain fatty acids 18:2(n-6) in liver tissue was reduced in the AL $(6.8 \% \pm 0.7)$ and in the CR $(6.5 \% \pm 1.4)$ group, compared with the initial value of $10.6 \% \pm 1.4$ (ST group). No significant differences were found between the AL and CR groups. The concentrations of the five major fatty acids in the food (DanEx 1562) itself decreased in the order 22:1(n-11) (15\%), 16:0 (14\%), 20:1(n-9) (12\%), $18: 1(n-9)(10 \%)$ and $22: 6(n-3)$, accounting for $7 \%$ of total fatty acids.

\section{Discussion}

We assumed that a $30 \%$ reduction in the food offered would not lead to starvation of the fish and we wished to prove this by comparing growth rate and body maintenance at the level of mitochondrial enzymes, which reflect mitochondrial density (CS) and respiratory capacity (CCO). Also, fatty acid analyses of livers from both turbot feeding groups confirmed that lipid stores derived from dietary lipids to a similar degree in AL and CR fish. At the end of the feeding experiment, the livers contained high proportions of longchain monounsaturated fatty acids 22:1(n-11) and 20:1(n-9), which were also abundant in the commercial feed. In ST group liver, the dominant fatty acids were 16:0, 20:5(n-3) and 22:6(n-3), known to be major phospholipid classes in fish membranes (Sargent 1976). Whereas the individual proportion of these fatty acid compounds varied between the CR and AL groups, their overall amount remained almost constant in all groups.

Although neither the final body length nor the weight in Table 1 differed significantly between the dietary treatments at the end of the experiment $(97$ days), a prognostic multiple regression growth model for body weight indicated a higher modelled weight gain in AL than in 30\%-CR fish (Fig. 2a). The difference in modelled mass gain appeared only after 28 days of calorie restriction, on day 70 of the experimental timeline. The prognostic values and standard errors from both growth models, transformed back to non-logarithmic values, are given in Fig. 2 as weight (a) and length (b) growth models. The trend of a higher body weight gain in the AL group is in line with, but certainly not only due to, the significantly higher liver wet weight in the AL group. The length model (Fig. 2b) provides no indication that AL fish grew faster than CR fish throughout differential feeding.

Deduced from a higher CS activity, AL fish maintained $20 \%$ higher mitochondrial density in the liver than CR fish. However, liver aerobic capacity (CCO) did not increase parallel to CS values in AL fish. Thus, while AL feeding may support liver growth and also a larger mitochondrial volume in the organ, weightspecific aerobic capacity and also the aerobic 

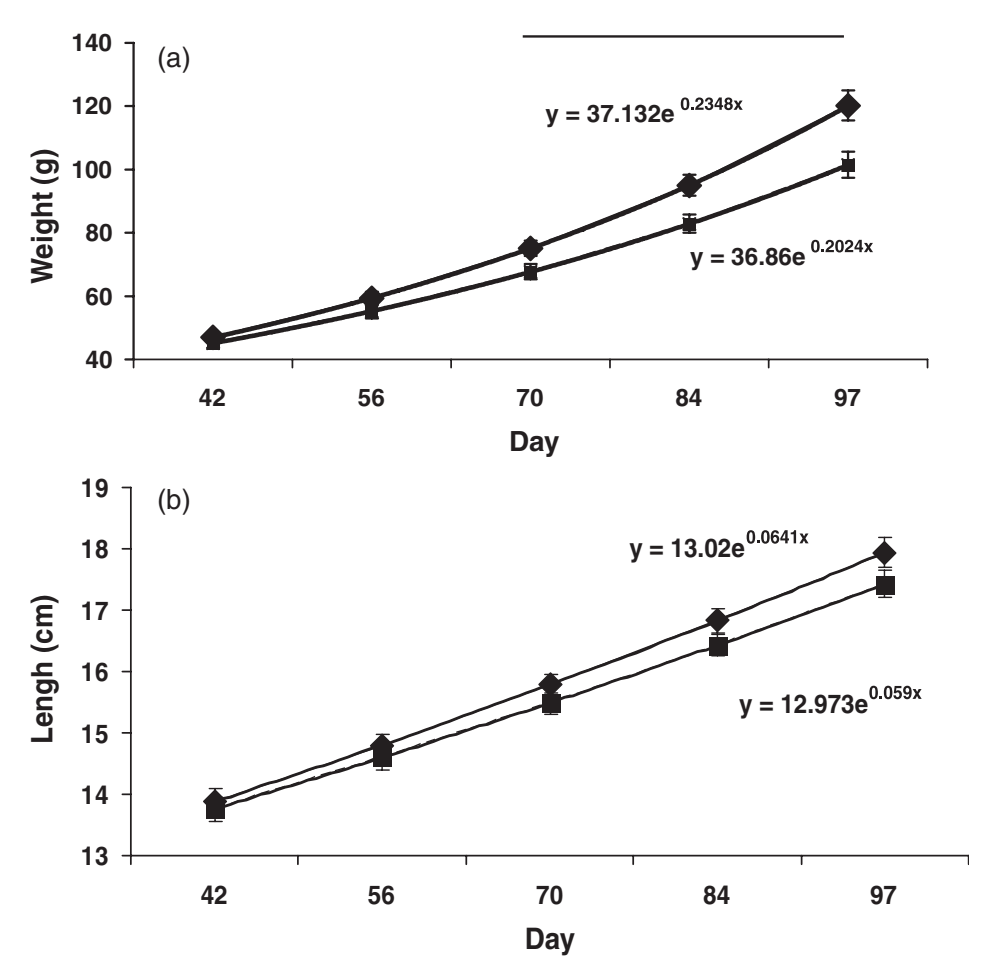

Figure 2 (a) Multiple regression growth model of ad libitum feeding (AL, -- -) and calorie restriction (CR, - $\mathbf{-}-$ ) turbot body fresh weight. Data as weight means \pm SEM, with $n=10$ on days $56,70,84$ and $n=36$ for days 36,97 on the experimental timeline. The CR feeding started on day 42 . The model indicated significantly lower body weight increment in CR compared with the AL fish from day 70 onwards below the black line. Equations for growth rate are given for each curve. (b) Multiple regression growth model of body length in ad libitum feeding (AL - -) and calorie reduced (CR, - - -) turbot feeding groups as forecast values. Data as weight means \pm SEM, with $n=10$ on days $56,70,84$ and $n=36$ for days 36,97 on the experimental timeline. No significant differences between slopes of both curves indicate calorie restriction to have no effect on animal body length.

capacity per mitochondrion (deduced from CCO:CS in Table 2) appear to be conserved better under CR than under AL conditions in liver tissue. Moreover, the equal respiratory capacity of CR and AL fish muscle is in line with the same swimming activity observed during feeding in both groups (only visual observations). In contrast, cod starved ( $0 \%$ feeding) over 16 weeks showed a $40-59 \%$ reduction in CS and $\mathrm{CCO}\left(\mathrm{Ug}^{-1}\right.$ wet weight) in white muscles (Martínez et al. 2003), and scorpionid fish fasted for 100 days lost 35\% (Scorpaena guttata) and 50\% (Sebastolobus alascanus) of CS activity when compared with ALfed controls (Yang \& Somero 1993). Interestingly, in the case of the scorpionids, the in situ values in freshly caught fish $\left(0.51 \mathrm{Ug}^{-1}\right.$ wet mass) were much closer to the fasted ones $\left(0.43 \mathrm{Ug}^{-1}\right.$ wet mass) than to AL-fed fish (0.89 $\mathrm{Ug}^{-1}$ wet mass), indicating the $\mathrm{AL}$ diet to be richer than the natural diet and indeed rather overfeeding the fish compared with field con- ditions. Similar findings were obtained for in situ and cultured cod (Martínez et al. 2003).

Lower mitochondrial densities in the liver resulting from the $30 \%$-CR condition might affect oxidative stress parameters in two different ways: firstly, in reducing mitochondrial density, CR may limit the production of ROS, ameliorating their damaging effects on tissue lipids and proteins. As a possible drawback, a higher respiratory capacity (CCO activity) per mitochondrion may possibly enhance ROS release from individual mitochondria in the liver, especially under stress when mitochondria release more ROS than under routine conditions (Abele, Philipp, Gonzalez \& Puntarulo 2007). Secondly, the 30\% feeding reduction could prevent the fish from stabilizing tissue redox rate (total glutathione and glutathione oxidation state) and antioxidant defence (enzyme and vitamin levels), and consequently may cause higher oxidative stress levels. 
Our measurements indicate that 30\%-CR in young turbot had no effect on total glutathione $\left(\mathrm{GSH}_{\text {total }}\right)$ concentration in either liver or muscle. The glutathione redox ratio in the liver was significantly more reduced in both groups at the end of the feeding experiment compared with the starting value. Also, there was no difference between AL and CR fish, indicating that higher mitochondrial aerobic capacities in liver mitochondria of CR fish have no pro-oxidant effect. Muscle redox ratio and tissue lipids (TBARS) were more oxidized in AL than in CR fish. Therefore, indications of oxidative stress are found in muscle tissue of AL-fed and not in CR turbot.

In a recent study of food deprivation in gilthead seabream, Sparus aurata (Pascual et al. 2003), fish received very low food offerings from $2 \%$ (control), $1,0.5$ down to $0 \%$ (full starvation) of animal wet weight over 46 days. The authors found oxidized glutathione (GSSG) and consequently tissue oxidation state to increase from the third week onwards in liver tissue of partially or fully food deprived fish. Tissue oxidation correlated positively with the extent of the food deprivation applied in the different groups. In parallel to the increase in GSSG levels, the lipid peroxidation marker malondialdehyde (MDA) accumulated in the liver of fish subject to reduced feeding. Morales et al. (2004) starved common dentex (Dentex dentex) over 5 weeks and found that liver glutathione peroxidase increased and liver glutathione reductase decreased following starvation. Although not reported in their study, this is bound to have had a net oxidizing effect on liver glutathione redox ratio. Thus, in contrast to this kind of prolonged strong food deprivation and complete starvation, turbot fed only $30 \%$ less than the AL food amount ( $4 \%$ of body weight) were able to stabilize tissue redox state in the liver and appeared even less oxidized in muscle tissue than $\mathrm{AL}$ fish.

Morales et al. (2004) and Pascual et al. (2003) found vastly increased MDA ('TBARS' in our study) levels in fish liver and deduced lipid peroxidation markers to be the most powerful indicator for oxidative stress under food deprivation in fish. In the present study, TBARS content per tissue wet mass decreased from the starting values independently of whether fish were fed an AL or a CR diet (Table 4), reflecting the absence of oxidative injury in both groups. As in our turbot study, TBARS (MDA) in seabream muscles was below $0.5 \mu \mathrm{molg}^{-1}$ fwt $\mathrm{g}$ under all feeding conditions (Pascual et al. 2003). Protein oxidation levels were not affected by $\mathrm{CR}$, indicating protein turnover and also antioxidant defence in the protein fraction of young turbot tissue to be equally protective in $\mathrm{AL}$ and CR fish.

\section{Differences between $\mathrm{CR}$ and starvation in fish}

In spite of differences in experimental design and in the parameters analysed in published papers, some significant differences emerge that distinguish responses to starvation and calorie restriction in fish. Whereas starvation for 5 weeks led to a significant loss of body weight in D. dentex (Morales et al. 2004), 8 weeks ( 55 days) of calorie restriction in young turbot did not lead to mass loss and only the calculated weight increment was lower in the CR group at the end of the experiment. Starvation reduced mitochondrial enzyme activities in white muscle of starved cod (Martínez et al. 2003), whereas in 30\%-CR turbot white muscle aerobic capacity remained constant. In dentex liver, starvation led to increased CS activity. In contrast, CR turbot CS activity was even reduced under calorie restriction in the liver.

Whereas our fish received $4 \%$ of body weight daily in the AL group (two times 2\%) and a 30\% reduction from this in the CR group over 8 weeks with no apparent effect on the HSI, in gilthead seabream the HSI remained unaffected as long as the animals received $2 \%$ of their body weight daily in a similar time span (46 days). However, HSI in seabream decreased when food offering was lowered to $1 \%$ of body weight or less per day or during complete starvation (Pascual et al. 2003).

Finally, liver glutathione redox ratio that tends to be more oxidized in starved fish is kept constant under CR. Neither lipid peroxidation markers per gram wet weight nor protein carbonyls accumulated under CR in young turbot, whereas MDA (TBARS) increased significantly under severe food deprivation or during complete starvation (Pascual et al. 2003; Morales et al. 2004). Although not investigated in our study, it appears likely that antioxidant enzyme activities are maintained constant during calorie restriction in turbot, whereas they can even be induced during starvation (Guderley et al. 2003; Morales et al. 2004).

In conclusion, we found that $30 \%$ calorie restriction in juvenile turbot had no adverse effects during 8 weeks. Production was not significantly diminished, and no negative effect was observed on the fitness and aerobic capacity of the fish or on oxidative stress parameters. Thus, calorie restriction may be included as a strategy in the feeding regime of fish that 
are to be transported (e.g. juvenile turbot to their grow-out site), to reduce excretion within the limited space of transport tanks. Longer experiments applying CR diets are needed to see if calorie restriction can also be applied as a more general strategy to ease feeding management without a major cutback on weight gain, and to demonstrate whether fish indeed remain healthier in aquaculture under reduced feeding.

\section{Acknowledgments}

We thank Eva Philipp, Stefanie Meyer and Timo Hirse for cooperation during the laboratory work, and Werner Wosniok from the University of Bremen for valuable support with the statistical analysis. Further, the experimental part with fish holding was shared with Azadeh Masoumi, Roman Herzog and Sabine Schäfer. Thanks are due to two anonymous referees for their constructive comments on an earlier version of this manuscript. The study was supported by grants from Bremerhavener Gesellschaft für Investitionsförderung und Stadtentwicklung mbH (BIS, BV 037).

\section{References}

Abele D., Philipp E., Gonzalez P. \& Puntarulo S. (2007) Marine invertebrate mitochondria and oxidative stress. Frontiers in Bioscience 12, 933-946.

Bodkin N.L., Alexander T.M., Ortmeyer H.K., Johnson E. \& Hansen B.C. (2002) Mortality and morbidity in laboratory-maintained rhesus monkeys and effects of long-term dietary restriction. The Journals of Gerontology Series A: Biological Sciences and Medical Sciences 58, B212-B219.

Bradford M.M. (1976) A rapid and sensitive method for the quantification of microgram quantities of protein utilizing the principle of protein-dye binding. Analytical Biochemistry 72, 248-254.

Couture R., Duti J.-D. \& Guderley H. (1998) Biochemical correlates of growth and condition in juvenile Atlantic cod (Gadus morhua) from Newfoundland. Canadian Journal of Fisheries and Aquatic Science 55, 1591-1598.

Duffy P.H., Feuers R.J., Leakey J.A., Nakamura K.D.,Turturro A. \& Hart R.W. (1989) Effect of chronic caloric restriction on physiological variables related to energy metabolism in the male Fischer 344 rat. Mechanical Aging Development 48, 117-133.

Fariss M.W. \& Reed D.J. (1987) High-performance liquid chromatography of thiols and disulfides: dinitrophenol derivatives. Methods in Enzymology 143, 101-109.

Folch J., Lees M. \& Sloane Stanley G.H. (1957) A simple method for the isolation and purification of total lipids from animal tissues. Journal of Biological Chemistry 226, 497-509.
Gamperl K.A. \& Farrell A.P. (2004) Cardiac plasticity in fishes: environmental influences and intraspecific differences. Journal of Experimental Biology 207, 2539-2550.

Graeve M., Albers C. \& Kattner G. (2005) Assimilation and biosynthesis of lipids in Arctic/Calanus/species based on feeding experiments with a $13 \mathrm{C}$ labelled diatom. Journal of Experimental Marine Biology and Ecology 317, 109-125.

Guderley H., Lapointe D., Bédard M. \& Dutil J.-D. (2003) Metabolic priorities during starvation: enzyme sparing in liver and white muscle of Atlantic cod, Gadus morhua L. Comparative Biochemistry and Physiology 135A, 347-356.

Kattner G. \& Fricke H.S.G. (1986) Simple gas-liquid chromatographic method for the simultaneous determination of fatty acids and alcohols in wax esters of marine organisms. Journal of Chromatography 361, 263-268.

Kirkwood T.B.L. \& Austad S.N. (2000) Why do we age? Nature 408, 233-238.

Koubova J. \& Guarente L. (2003) How does calorie restriction work? Genes and Development, doi:10.1101/grad 1052903.

Ku H.H., Brunk U.T. \& Sohal R.S. (1993) Relationship between mitochondrial superoxide and hydrogen peroxide production and longevity of mammalian species. Free Radical Biology and Medicine 15, 621-627.

Lamming D.W., Wood J.G. \& Sinclair D.A. (2004) Small molecules that regulate lifespan: evidence for xenohormesis. Molecular Microbiology, doi:10.1111/j.: 1365-2958.

Levine R.L., Garland D., Oliver C.N., Amici A., Climent I., Lenz A.-G., Ahn B.-W., Shaltiel S. \& Stadtman E.R. (1990) Determination of carbonyl content in oxidatively modified proteins. Methods in Enzymology 49, 464-478.

Martínez M., Guderley H., Dutil J.D., Winger P.D., He P. \& Walsh S.J. (2003) Condition, prolonged swimming performance and muscle capacities of cod Gadus morhua. The Journal of Experimental Biology 206, 503-511.

Mock G., White R. \& Wagener A. (2001) Farming Fish: The aquaculture boom. Vanasselt (ed.) World Resources 1998 1999, updated for Earth Trends. 5pp.

Morales A.E., Perez-Jimenez A., Hidalgo M.C., Abellán E. \& Cardenete G. (2004) Oxidative stress and antioxidant defenses after prolonged starvation in Dentex dentex liver. Comparative Biochemistry Physiology 139C, 153-161.

Moyes C.D., Mathieu-Costello O.A.,Tsuchiya N., Filburn C. \& Hansford R.G. (1997) Mitochondrial biogenesis during cellular differentiation. American Journal of Physiology 272, C1345-C1351.

Pascual P., Pedrajas J.R.,Toribio F., Lopez-Barea J. \& Peinado J. (2003) Effect of food deprivation on oxidative stress biomarkers in fish (Sparus aurata). Chemico-Biological Interactions 145, 191-199.

Randall D., Bolis L. \& Agradi E. (1990) Fish in human nutrition research and the implications for aquaculture. Ambio 19, $272-275$.

Sargent J.R. (1976) The structure, metabolism and function of lipids in marine organisms. In: Biochemical and Biophy- 
sical Perspectives in Marine Biology ed. by J.C. Malins \& J.R. Sargent), pp. 149-212. Academic Press, London, UK.

Shepherd C.J. \& Bromage N.R. (1988) Intensive Fish Farming. Oxford: Blackwell Scientific Publications (BSP) Professional Books, Melbourne, Australia, pp. 1-416.

Sidell B.D., Driedzic W.R., Stowe D.B. \& Johnston I.A. (1987) Biochemical correlations of power development and metabolic fuel preference in fish hearts. Physiological Zoology 60, 221-232.

Skalski G.T., Picha M.E., Gilliam J.F. \& Borski R.J. (2005) Variable intake, compensatory growth, and increased growth efficiency in fish: models and mechanics. Ecology 86, 1452-1462.

Sohal R.S. \& Weindruch R. (1996) Oxidative stress, caloric restriction, and aging. Science 273, 59-63.

Stuart J.A. \& Brown M.F. (2006) Energy, quiescence and the cellular basis of animal life spans. Comparative Biochemistry Physiology 143A, 12-23.

Uchiyama M. \& Mihara M. (1978) Determination of malonaldehyde precursor in tissues by thiobarbituric acid test. Analytical Biochemistry 86, 271-278.
Weindruch R., Keenan K.P., Carney J.M., Fernandez G., Feuers R.J., Floyd R.A., Halter J.B., Ramsey J.J., Richardson A., Roth G.S. \& Spindler S.R. (2001) Caloric restriction mimetics: metabolic interventions. Journal of Gerontology 56A, 20-33.

Warner H.R. \& Starke-Reed P. (1997) Oxidative stress and aging. In: Oxygen, Gene Expression and Cellular Function ed. by L.B. Clerch \& D.J. Massaro), pp. 139-168. Marcel Dekker, New York, NY, USA.

Yang T.-H. \& Somero G.N. (1993) Effects of feeding and food deprivation on oxygen consumption, muscle protein concentration and activities of energy metabolism enzymes in muscle and brain of shallow-living (Scorpaena guttata) and deep-living (Sebastolobus alascanus) scorpaenid fishes. Journal of Experimental Biology 181, 213-232.

Zhu X., Cui Y., Ali M. \& Wootton R.J. (2001) Comparison of compensatory growth responses of threespined stickleback and minnow following similar food deprivation protocols. Journal of Fish Biology $\mathbf{5 8}$, 1149-1165. 